\title{
KESIAPSIAGAAN KOMUNITAS SEKOLAH DALAM MENGHADAPI BENCANA DI KABUPATEN MAGELANG
}

\author{
Cindrawaty Lesmana, Nurul Purborini \\ ${ }^{1}$ Jurusan Teknik Sipil, Fakultas Teknik, Universitas Kristen Maranatha, \\ email: cindra@eng.maranatha.edu \\ 2 Jurusan Keperawatan, Fakultas Ilmu Kesehatan, \\ Universitas Muhammadiyah Magelang, \\ email: ners.nurul@gmail.com
}

\begin{abstract}
ABSTRAK
Sekolah siaga bencana adalah kunci utama untuk melindungi anak-anak dan generasi muda dalam membentuk lingkungan belajar yang kondusif dan aman dari bencana yang tidak dapat terhindarkan. Pencapaian kesiapsiagaan sekolah sangatlah penting mengingat Indonesia termasuk negara dengan resiko bencana yang tinggi. Data dikumpulkan dari komponen sekolah seperti kepala sekolah, guru, dan tenaga administratif untuk meninjau kesiapsiagaan sekolah dalam pengurangan resiko bencana di Kabupaten Magelang, Jawa Tengah, Indonesia yang terancam bahaya lahar dari Gunung Merapi. Hasil survey menunjukkan bahwa kesiapsiagaan sekolah masih perlu ditingkatkan.
\end{abstract}

Kata kunci: sekolah siaga bencana, kesiapsiagaan bencana, manajemen bencana

\section{LATAR BELAKANG}

Bencana alam seperti gempa, erupsi dari gunung berapi, banjir, dan lainnya dapat berdampak secara langsung dan tidak langsung pada kerugian material, lingkungan, pendidikan dan sosial ekonomik dalam komunitas (Carr, 1932; UNESCO, 2003; ADPC, 2008; IFC, 2010; Seyle, Widyatmoko et al., 2013). The Economy and Environment Program for Southeast Asia (EEPSEA) menyatakan bahwa Indonesia adalah salah satu negara sangat rawan dengan perubahan iklim di peta perubahan iklim untuk Asia Tenggara (Yusuf and Francisco, 2009). Indonesia secara geografis termasuk ke dalam wilayah yang tidak stabil dan rawan bencana. Hal ini dikarenakan letak geografis Indonesia yang diapit lempeng Eurasia Asia - Australia serta lempeng Pasifik dan Philipine yang cukup aktif.

Menurut data statistik bencana di Indonesia yang terangkum pada Tabel 1, banjir merupakan bencana yang paling sering terjadi dan berdampak terbesar untuk masyarakat (BNPB, 2014). Bencana gempa dan longsor merupakan bencana yang menghasilkan banyak korban jiwa. Selain itu, gempa juga berdampak pada kerusakan gedung sekolah. Indonesia juga termasuk rawan 
terhadap bencana gunung berapi. Indonesia memiliki 400 gunung berapi dan 129 diantaranya adalah gunung berapi yang masih aktif.

Tabel 1 Statistik bencana di Indonesia periode 2004-2014

\begin{tabular}{lrrr}
\hline Jenis bencana & Terdampak & Meninggal & Kerusakan sekolah \\
\hline Gempa & $2,906,647$ & 8,324 & 20,970 \\
Banjir & $17,283,349$ & 2,013 & 5,170 \\
Gunung berapi & 308,762 & 427 & 617 \\
Longsor & 85,081 & 1,673 & 99 \\
\hline
\end{tabular}

Sumber: $(B N P B, 2014)$

Bencana dapat berdampak pada melemahnya perekonomian dan ketahanan pemerintahan. Bencana juga dapat memberikan dampak pada dunia pendidikan. Kerugian pada elemen sekolah seperti guru dan murid, proses belajar mengajar, properti, dan penyediaan akibat bencana, mengakibatkan jutaan masa depan generasi muda terancam. Terhentinya pendidikan akibat dari konflik dan bencana alam merupakan sebab utama dari keluarnya anak-anak dan generasi muda dari jalur pendidikan (Pereznieto and Harding, 2013). Ditiadakannya hak mereka untuk mendapatkan pendidikan merenggut kesempatan mereka untuk mengembangkan diri untuk keluar dari kemiskinan dan marginalisasi (Pereznieto and Harding, 2013). Oleh sebab itu, bencana alam berdampak pada anak-anak dan generasi muda.

Bencana menyebabkan banyak sekolah yang rusak maupun hancur. Banyaknya sekolah yang hancur maupun rusak pada saat gempa dan Tsunami Aceh (2004), Gempa Yogyakarta (2006), Erupsi Gunung Merapi (2010), dan bencana alam lainnya mengakibatkan terhentinya kegiatan belajar mengajar. Hal ini menunjukkan bahwa bencana tidak dapat dihindari akan tetapi komunitas dapat bersiap untuk mengurangi bahaya bencana. Oleh sebab itu, pengenalan dan pengurangan resiko bencana harus dilakukan sejak dini.

Pengurangan resiko bencana di sekolah adalah sangat penting mengingat Indonesia termasuk negara yang rawan akan bencana (KPB, 2011). Pencapaian 
kesiapsiagaan bencana sangat penting terutama untuk daerah-daerah yang sering terjadi bencana. Pengalaman akan bencana alama yang berulang diyakini menjadi alasan untuk komunitas untuk lebih siap siaga. Jawa Tengah teridentifikasi di zona dengan potensial resiko bencana tinggi (BAPENAS, 2010). Kabupaten Magelang adalah salah satu daerah yang berada di kaki Gunung Merapi. Kampaye nasional Indonesia tahun 2010, 1 juta sekolah dan rumah sakit aman, telah diluncurkan di Magelang, sehingga seharusnya sekolah-sekolah tersebut telah siap siaga terhadap bencana. Penelitian ini bertujuan untuk melihat sejauh mana kesiapsiagaan pengurangan resiko bencana pada SMA di Kabupaten Magelang. Apakah pengalaman berulang akan bencana memicu kesiapsiagaan akan pengurangan resiko bencana di sekolah? Penelitian ini akan berguna bagi pembuat kebijakan, lembaga swadaya masyarakat, yayasan sosial, aparat pemerintahan, peneliti, dan komuitas sekolah untuk mendapatkan realita kesiapsiagaan bencana sekolah di daerah yang rawan akan bencana.

\section{SEKOLAH SIAGA BENCANA}

Pada tahun 2006, hasil penelitian dari Lembaga Ilmu Pengetahuan Indonesia (LIPI) bekerjasama dengan United Nations Educational, Scientific and Cultural Organization (UNESCO) di tiga daerah di Indonesia (Aceh, Bengkulu, dan Padang) menyatakan bahwa kesiapsiagaan bencana untuk sekolah adalah paling rendah dibandingkan dengan kesiapsiagaan rumah tinggal dan masyarakat (LIPI, 2007). Diawali pada Mei 2010, Platfom Nasional untuk Pengurangan Resiko Bencana (Planas-PRB) bekerjasama dengan patner lainnya melunjurkan kampanye "1 juta sekolah dan rumah sakit aman" di beberapa kota besar di Indonesia seperti: Jakarta, Yogyakarta, Aceh, Sumatera Barat (Padang), Jawa Barat (Bandung dan Sukabumi), Jawa Tengah (Magelang dan Kebumen), dan Jawa Timur (Surabaya dan Jember). Konsorsium pendidikan bencana di Indonesia (KPB) juga meluncurkan kerangka kerja sekolah siaga bencana dan strategi pengurangan resiko bencana di sekolah pada tahun 2011.

Bencana di sekolah dapat didefinisikan sebagai segala kejadian yang mengakibatkan titik balik, seringkali penderitaan, tekanan, atau ketidakteraturan fungsi secara fisik dan atau psikologis (Reeves, Kanan et al., 2010). Sekolah Siaga 
Bencana (SSB) meliputi pengembangan prosedur dan tindakan dalam sekolah untuk memfasilitasi koordinasi dan respon yang sigap dan efektif ketika terjadi bencana (OSDFS, 2007). SSB mencakup juga pra-pembentukan pos komando, area evakuasi, tim bencana dan perannya, persiapan peralatan dan perlengkapan, simulasi dan praktek kesiap siagaan dengan mitra dari multi lembaga (IFC, 2010). Hal ini berarti SSB adalah sekolah yang memiliki kemampuan untuk mengatasi bencana di lingkungan sekitarnya yang diukur dari rencana penanggulangan bencana (pra-bencana, bencana darurat, dan setelah bencana), logistic, keamanan di lingkungan belajar, infrastruktur, sistem darurat, prosedur operasional yang telah distandarkan, dan sistem peringatan dini (KPB, 2011).

Federal Emergency Management Agency (FEMA) membagi tanggung jawab kepala sekolah, guru, tenaga administratif dan pihak lainnya yang terkait di kesiap siagaan sekolah dalam Multi-Phase Comprehensive Safe School Plans (FEMA, 2011). Kemampuan setiap personil sangat berpengaruh pada kesuksesan SSB. Inter-Agency Network for Education in Emergencies (INEE) pada Planning in an Emergency Checklist mencantumkan standar minimum untuk sekolah dalam menanggulangi bencana. Pendidikan mengenai bencana perlu dimasukan ke dalam sistem pendidikan, kurikulum dan pengajaran, serta kesinambungan pendidikan dalam situasi bencana (INEE, 2004). Tujuan dari SSB adalah menciptakan kesiapsiagaan dan budaya aman di lingkungan sekolah serta membangun kekuatan setiap elemen sekolah untuk Pengurangan Resiko Bencana - PRB (KPB, 2011). Dalam perkembangannya, empat parameter ditetapkan sebagai parameter kesiapsiagaan sekolah, yaitu: 1. Sikap dan tindakan; 2. Kebijakan sekolah; 3. Perencanaan kesiapsiagaan; dan 4. Mobilisasi sumber daya.

\section{METODOLOGI}

Data dikumpulkan dengan metode kuantitatif melalui survei kuesioner berdasarkan KPB (2011). Empat parameter tersebut kemudian ditinjau ulang dan diadaptasi dengan literatur lainnya, yaitu: sikap dan tindakan (INEE, 2004; Marla Petal and Rebekah Green 2008; IFC, 2010; KPB, 2011), kebijakan sekolah (OSDFS, 2003; IFC, 2010; FEMA, 2011; KPB, 2011), perencanaan kesiapsiagaan (OSDFS, 2003; IFC, 2010; FEMA, 2011; KPB, 2011), dan mobilisasi sumber 
daya (OSDFS, 2003; IFC, 2010; FEMA, 2011; KPB, 2011). Setiap indikator diukur dari tanggapan dari responden dalam skala Likert berderajat 4 ( $1=$ belum diimplementasikan sama sekali, 2 = baru dalam pengembangan, 3 = dalam pengembangan sampai batasan tertentu, dan $4=$ diimplementasikan secara lengkap). Beberapa indikator dalam kuesioner meliputi "sekolah memiliki dokumen kesiap siagaan sekolah yang direview secara rutin dan diperbaharui secara partisipatif”, "adanya bangunan sekolah yang aman terhadap bencana", "sekolah memiliki lokasi evakuasi yang tersosialisasikan serta disepakati oleh seluruh komponen sekolah, orang tua murid, masyarakat sekitar, dan pemerintah daerah", dan lainnya.

Tabel 2 Karakteristik responden

\begin{tabular}{ll}
\hline Indikator & Total \\
\hline Jumlah responden & $80(100 \%)$ \\
Peran di sekolah & \\
Kepala sekolah & $3(3.75 \%)$ \\
Guru & $54(67.50 \%)$ \\
Administrasi & $23(28.75 \%)$ \\
Jenis kelamin & \\
Pria & $35(43.75 \%)$ \\
Wanita & $45(56.25 \%)$ \\
Lama kerja & \\
0-3 tahun & $24(30.00 \%)$ \\
3-6 tahun & $10(12.50 \%)$ \\
6-9 tahun & $9(11.25 \%)$ \\
$>9$ tahun & $37(46.25 \%)$ \\
\hline
\end{tabular}

\section{SAMPEL}

Di Jawa Tengah terdapat 5 gunung berapi yang tergolong aktif dan salah satu diantaranya adalah Gunung Merapi. Data diambil dari kuesioner yang disebarkan pada tiga Sekolah Menengah Kejuruan (SMK) di Kabupaten Magelang (Muntilan 
dan Salam) yang terdampak bencana lahar dingin dari Gunung Merapi, Magelang - Indonesia pada tahun 2010. Total responden adalah 80 orang yang terdiri dari kepala sekolah, guru, dan tenaga administratif sekolah. Karakteristik responden lebih lengkapnya dapat dilihat di Tabel 2.

\subsection{Analisis dan Pembahasan}

Walaupun jumlah sampel relatif kecil untuk pengolahan data statistik, penelitian telah membuktikan bahwa aturan untuk jumlah sampel minimum adalah tidak terlalu valid dan berguna (MacCallum, Widaman et al., 1999; Preacher and MacCallum, 2002). Sulit disimpulkan jumlah sampel absolut adalah penting untuk pengolahan data, tetapi minimum sampel tergantung pada aturan lainnya seperti: angka communality tinggi yang menyatakan sampel terdistribusi normal dengan baik (MacCallum, Widaman et al., 2001), angka ini harus lebih besar dari 0.6 dengan rata-rata keseluruhan minimum adalah 0.7 , dan faktor beban di atas 0.8 termasuk tinggi, di atas 0.6 termasuk moderat, dan di bawah 0.4 dianggap lemah (Velicer and Fava, 1998).

Pada penelitian ini, Exploratory factor analysis (EFA) dianalisis dengan mengunakan SPSS v.17 untuk menentukan jumlah indikator yang mempengaruhi setiap parameter (Yong and Pearce, 2013). Pada akhirnya faktor beban minimum adalah 0.946 untuk sikap dan tindakan, 0.650 untuk kebijakan sekolah, 0.702 untuk perencanaan kesiapsiagaan, dan 0.797 untuk mobilisasi sumber daya. Nilai dari Cronbach's alpha adalah 0.867 yang berarti relasi yang kuat antar parameter.

Sekolah siaga bencana adalah sekolah yang memberi perhatian bagaimana resiko bencana dapat dicegah dan diatasi secara efektif (Ryan, Campbell et al., 1999; Atack, Parker et al., 2009). Sikap dan tindakan dalam SSB adalah persepsi pengetahuan dan kemampuan dari komponen sekolah untuk mengatasi bahaya bencana secara efektif. Tabel 3 mengilustrasikan masih kurangnya sikap dan tindakan komponen sekolah dalam pengetahuan dan upaya-upaya Penanganan Resiko Bencana (PRB). Hal ini terlihat dari nilai rata-rata yang relatif kecil mendekati $1(\mu=1.20)$ dimana 1 berarti belum ada implementasi. Sosialisasi SSB telah dilakukan oleh pemerintah akan tetapi implementasi di internal sekolah masih sangatlah kurang. 
Kebijaksanaan sekolah meliputi kebijakan, kesepakatan, maupun peraturan sekolah untuk PRB. Pondasi dan petunjuk dalam PRB dalam pengembangan yang dapat dimplementasikan sebagian. Hal ini terlihat pada rata-rata $=2.23$ pada Tabel 3. Rata-rata sekolah telah siap dengan rencana alternatif pendidikan pada saat bencana untuk kesinambungan proses belajar mengajar pada saat kritis.

Tabel 3 Analisis deskriptif SSB

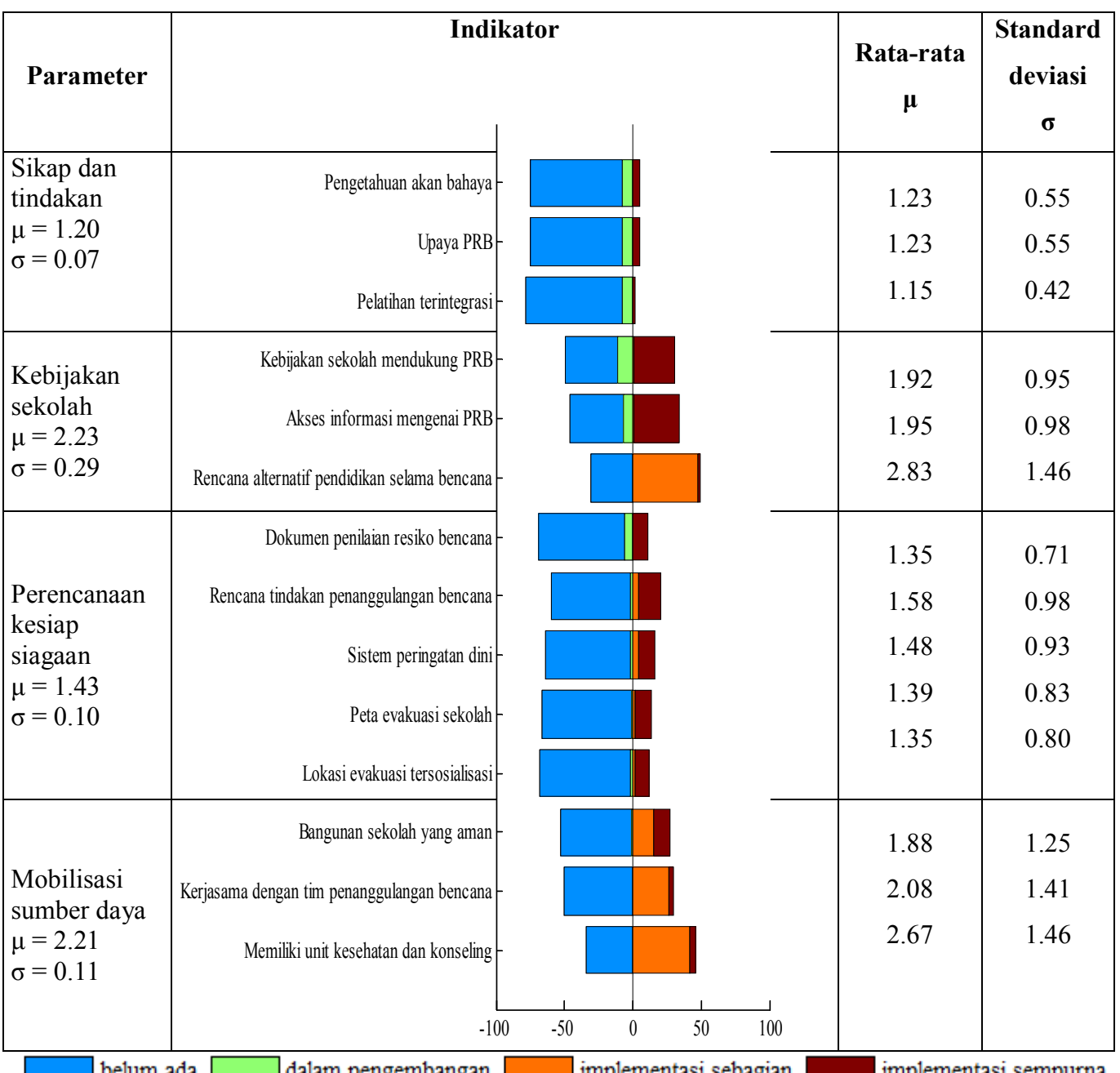

Note: untuk keseluruhan SSB meliputi empat parameter, rata-rata $=1.77$ dan standar deviasi $=0.10$.

Perencanaan kesiapsiagaan adalah tahapan menyiapkan tindakan yang efektif dan efisien saat bencana, termasuk dokumenn dan rencana sistem lokal beserta penyesuaian (KPB, 2011). Kurangnya implementasi sekolah dalam perencanaan 
kesiapsiagaan dapat terlihat pada Tabel 3. Pengembangan sistem peringatan dini di sekolah, peta dan sosialisasi lokasi evakuasi harus ditingkatkan. Pengambilan keputusan dan alur koordinasi untuk penanganan bencana harus berlangsung dengan cepat dan fleksibel saat terjadinya bencana. Keefektifan dan kecepatan ini bertujuan untuk menyelesaikan masalah yang mungkin terjadi terkait terbatasnya informasi saat bencana (FEMA, 2011). Oleh sebab itu, rencana tindakan penanggulangan bencana perlu dikembangkan lebih lanjut untuk mencegah kepanikan pada saat menghadapi bahaya bencana. Walaupun sosialisasi SSB dan kampanye 1 juta sekolah dan rumah sakit aman telah diluncurkan, hasil survei menunjukkan bahwa perencanaan kesiapsiagaan sekolah adalah hasil kerja pihak luar sekolah, seperti: pemerintah dan institusi lainnya. Dikarenakan prakarsa dari SSB belum dilakukan oleh sekolah sendiri, prosedur maupun informasi tentang kesiapsiagaan bencana hanyalah dokumen yang tersimpan dan sekolah sendiri belum menciptakan lingkungan yang aman dari bahaya bencana.

SSB bergantung pada persiapan dari sumber daya manusia, fasilitas dan infrastruktur dari sekolah dalam PRB maupun penanggulangan bahaya bencana. Mobilisasi sumber daya meliputi kapasitas sekolah, permerintah, komunitas di sekitar lingkungan sekolah dan pihak luar lainnya yang terkait (KPB, 2011). Kualitas gedung sekolah seperti perkuatan struktur dari bangunan itu sendiri, tata letak dan desain kelas, fasilitas, dan infrastruktur yang aman, dll. perlu ditingkatkan. Banyak responden meragukan kemampuan gedung sekolah mereka pada saat menghadapi bencana $(\mu=1.88)$. Rata-rata sekolah telah dilengkapi dengan fasilitas unit kesehatan dan bimbingan konseling yang siap bertindak pada pra-bencana, saat bencana, dan setelah bencana $(\mu=2.67)$. Secara umum, mobilisasi sumber daya perlu ditingkatkan. Sekolah harus memiliki kesiapan dan kesiagaan terhadap bencana, bukan hanya mengandalkan instruksi dan bantuan dari pihak luar.

Bencana alam sulit diprediksi, baik waktu terjadi maupun dampaknya. Oleh sebab tu, penanganan bencana yang efektif perlu disiapkan. Penanganan bencana yang efektif dapat mengurangi dampak dari bencana yang terjadi (Cornell and Sheras, 1998; UNESCO, 2003; FEMA, 2012; INEE, 2012). Sekolah juga harus memiliki kesiapan dalam menghadapi bencana. Saat terjadi bencana, setiap 
komponen sekolah harus siap sehingga dapat berkoordinasi secara efektif dan berbagi informasi yang sama (Paine and Sprague, 1999; Reeves, Kanan et al., 2010).

Kampanye "1 juta sekolah dan rumah sakit aman" telah diluncurkan di Magelang sejak 2010, akan tetapi hasil survei menunjukkan kebijakan dan kampanye masih menjadi tantangan terbesar dalam mengimplementasikan dokumen dan aturan yang ada untuk menghasilkan lingkungan sekolah yang aman terutama di daerah yang rawan bahaya bencana. Upaya dari pihak luar untuk SSB lebih besar daripada kesadaran komponen sekolah untuk menghasilkan lingkungan sekolah yang aman. Rencana dan persiapan yang baik disusul dengan implementasinya pada saat penanganan bencana dapat mengurangi dampak negatif dari bahaya bencana (FEMA, 2012). Implementasi SSB adalah tantangan bagi sekolah untuk memperkuat PRB dan pihak luar untuk menyadarkan sekolah akan pentingnya mengimplementasikan SSB.

\subsection{Pengalaman berulang akan bencana dan sekolah siaga bencana}

Pengalaman pribadi akan menghasilkan daya adaptasi dalam kesiapsiagaan untuk pengalaman yang berikutnya (Mulilis and Duval, 1997; Karanci, Aksit et al., 2005). Pengalaman dari peristiwa sebelumnya akan meningkatkan persepsi resiko tentang bahaya bencana dan memperkuat motivasi individu dalam perilaku kesiapsiagaan bencana (Terpstra, 2011). Penelitian ini meninjau apakah pengalaman berulang terhadap bencana dapat memicu kesiapsiagaan dan pengurangan resiko bencana di sekolah.

\section{Tabel 4 Korelasi model antara pengalamaan berulang}

akan bencana dan SBB

\begin{tabular}{|l|r|r|r|r|}
\hline & $\begin{array}{l}\text { Sikap dan } \\
\text { tidakan }\end{array}$ & $\begin{array}{l}\text { Kebijakan } \\
\text { sekolah }\end{array}$ & $\begin{array}{l}\text { Perencanaan } \\
\text { kesiap siagaan }\end{array}$ & $\begin{array}{l}\text { Mobilisasi } \\
\text { sumber daya }\end{array}$ \\
\hline $\begin{array}{l}\text { Pengalaman } \\
\text { bencana }\end{array}$ & $0.135^{*}$ & 0.066 & 0.081 & 0.203 \\
Intercept & $3.598^{* * *}$ & $2.701^{* * *}$ & $3.461^{* * *}$ & $2.497^{* * *}$ \\
\hline $\begin{array}{l}\text { Adjusted } R^{2} \\
\text { P-value }\end{array}$ & 0.073 & 0.005 & 0.015 & 0.027 \\
& 0.024 & 0.581 & 0.312 & 0.181 \\
\hline
\end{tabular}

$* * * \mathrm{p}<0.001,{ }^{* *} \mathrm{p}<0.01,{ }^{*} \mathrm{p}<0.05,{ }^{+} \mathrm{p}<0.1$ 
Tabel 4 menampilkan hasil korelasi hubungan dari pengalaman ke parameter dalam SSB. Pengalaman berulang akan bencana secara statistik signifikan hanya terhadap sikap dan tindakan sekolah dalam PRB $(\mathrm{p}<0.05)$ dan tidak signifikan untuk kebijakan sekolah, perencanaan kesiapsiagaan, dan mobilisasi sumber daya. Kebijakan sekolah dan perencanaan kesiapsiagaan lebih pada dokumen dan prosedur penanganan bencana dimana diperlukan upaya yang lebih daripada sekedar mengandalkan pengalaman. Pada umumnya individu yang pernah mengalami bencana akan lebih sensitif terhadap sistem peringatan dini dan lebih antusias bekerjasama dalam penangananan bencana (Anderson, 1969), akan tetapi, pengalaman dapat juga menurunkan anggapan akan ancaman bahaya di masa depan (Peacock, Brody et al., 2005).

Pengalaman pribadi dapat memicu perasaan bersalah yang berpotensial untuk adaptasi menghadapi kejadian di masa yang akan datang (Terpstra, 2011). Pengalaman sebelumnya menciptakan pengetahuan akan bahaya bencana dan mendorong usaha penyelamatan diri dari bahaya bencana. Dalam hal ini komponen sekolah belajar dari pengalaman bencana sebelumnya, akan tetapi pengalaman pribadi tidaklah cukup sebab pengalaman dapat membawa individu untuk menjadi lebih baik atau lebih buruk dalam menghadapi kejadian di masa depan (Wang and Yuan, 2011). Kekurangan dari kognitif manusia, kebiasaan, struktur dan karakter dari organisasi dan lingkungannya menciptakan masalah dalam pembelajaran dari pengalaman hidup (Milton, 2010). Oleh sebab itu perlunya perencanaan dan kebijakan sekolah serta program pelatihan untuk memastikan terlaksananya kesiap siagaan akan bencana (Karanci, Aksit et al., 2005).

\section{KESIMPULAN}

Implementasi sekolah siaga bencana sangatlah penting terutama di daerah rawan bencana. Secara umum kesiapsiagaan sekolah perlu ditingkatkan untuk mendukung kampanye "1 juta sekolah dan rumah sakit aman" dan juga menciptakan lingkungan sekolah yang aman dari bahaya bencana. Rata-rata dari hampir semua parameter SSB yang relatif kecil menandakan kesiapsiagaan komponen sekolah yang masih di bawah harapan. Hal ini dikarenakan masih 
barunya sosialisasi SSB ini, dimana beberapa area di Kabupaten Magelang mendapat giliran pada tahun 2013. Perlunya peninjauan ulang bagaimana sosialisasi SSB dapat meningkatkan kesadaran yang lebih baik dari komponen sekolah untuk membentuk lingkungan sekolah yang aman dari bahaya bencana.

Kunci keberhasilan dari PRB adalah menciptakan kestabilan kesiapsiagaan pada waktu sebelum terjadi bencana (Graham, Shirm et al., 2006). Pengalaman berulang akan bencana tidaklah cukup, maka pelatihan yang terintegrasi dan sosialisasi lebih lanjut akan SSB sangatlah diperlukan. Rencana yang terdokumentasi harus mulai dibuat, disosialisasikan dan disimulasikan, sebab organisasi termasuk sekolah harus selalu beranggapan bahwa tulisan saja tidak cukup (Kano and Bourque, 2007). Rencana tertulis harus didukung dengan pelatihan dan simulasi nyata akan penanganan bencana.

Penelitian diselenggarakan di dua daerah pada Kabupaten Magelang. Sampel sekolah yang diambil adalah sekolah yang rawan bencana lahar dingin, maka diasumsikan lebih siap menghadapi bencana. Kampanye "1 juta sekolah dan rumah sakit aman" telah disosialisasikan secara baik pada tahun 2013 di daerah tersebut hanya saja penelitian menunjukan bahwa kesiapsiagaan sekolah masih sangatlah kurang dan perlu dikembangankan lebih lanjut. Oleh sebab itu kerjasama dari kedua belah pihak, sekolah dan pihak luar, perlu terus ditingkatkan untuk menciptakan lingkungan sekolah yang aman dari bahaya bencana di Indonesia.

\section{DAFTAR PUSTAKA}

1. ADPC (2008), A study on impact of disasters on the education sector in Cambodia, Bangkok, Asian Disaster Preparedness Center (ADPC).

2. Anderson, W. A. (1969), Disaster Warning and Communication Processes in Two Communities, Journal of Communication 19(2): 92-104.

3. Atack, L., K. Parker, et al. (2009), The impact of an online interprofessional course in disaster management competency and attitude towards interprofessional learning, Journal of Interprofessional Care 23(6): 586-598.

4. BAPENAS (2010), National platform for disaster risk reduction (RANPRB) 2010-2012, Jakarta.

5. BNPB. (2014), Data dan informasi bencana Indonesia, Retrieved 31 Maret 2014, from http://dibi.bnpb.go.id/. 
6. Carr, L. J. (1932), Disaster and the sequence-pattern concept of social change, American Journal of Sociology 38(2): 207-218.

7. Cornell, D. G. and P. L. Sheras (1998), Common errors in school crisis response: Learning from our mistakes, Psychology in The Schools 35(3): 297-307.

8. FEMA (2011), Sample school emergency operations plan.

9. FEMA (2012), Crisis response and disaster resilience 2030: Forging strategic action in an age of uncertainty, Washington, DC, Federal Emergency Management Agency.

10. Graham, J., S. Shirm, et al. (2006), Mass-Casualty Events at Schools: A National Preparedness Survey, Pediatrics 117(1): e8-e15.

11. IFC (2010), Disaster and emergency preparedness: Guidance for schools, Washington, DC, International Finance Coorperation - World Bank Group.

12. INEE (2004), Minimum standards for education in emergencies, chronic crises and early reconstruction, Canada, Inter-Agency Network for Education in Emergencies (INEE).

13. INEE (2012), Minimum standards for education: Preparedness, response, recovery, Canada, Inter-Agency Network for Education in Emergencies (INEE).

14. Kano, M. and L. B. Bourque (2007), Experiences With and Preparedness for Emergencies and Disasters Among Public Schools in California, NASSP Bulletin 91(3): 201-218.

15. Karanci, A. N., B. Aksit, et al. (2005), Impact of A Community Disaster Awareness Training Program in Turkey: Does It Influence HazardRelated Cognitions and Preparedness Behaviors, Social Behavior and Personality An International Journal 33(3): 243-258.

16. KPB (2011), Kerangka kerja sekolah siap bencana, Jakarta, Konsorsium Pendidikan Bencana (KPB)

17. LIPI (2007), Study of community crisis preparedness 2006-2007 (in Bahasa), Jakarta, Indonesian Institute of Science.

18. MacCallum, R. C., K. F. Widaman, et al. (1999), Sample size in factor analysis, Psychological Methods 4(1): 84-99.

19. MacCallum, R. C., K. F. Widaman, et al. (2001), Sample size in factor analysis: The role of model error., Multivariate Behavioral Research 36(4): 611-637.

20. Marla Petal and Rebekah Green(2008), School disaster readiness: Lessons from the first great southern california shakeout, Los Angeles California,

Risk RED \& Coalition for Global School Safety \& Disaster Prevention Ed ucation: International School Safety Observation Team.

21. Milton, N. (2010), The lessons learned handbook: Practical approaches to learning from experience

22. Chandos Publishing.

23. Mulilis, J.-P. and T. S. Duval (1997), The PrE Model of Coping and Tornado Preparedness: Moderating Effects of Responsibility, Journal of Applied Social Psychology 27(19): 1750-1766. 
24. OSDFS (2003), Practical information on crisis planning: A guide for schools and communities, Washington, D.C., Office of Safe and Drug-Free Schools, U.S. Department of Education, ED-01-CO-0082/0006.

25. OSDFS (2007), Practical information on crisis planning: A guide for schools and communities, Washington, D.C., Office of Safe and Drug-Free Schools, U.S. Department of Education.

26. Paine, C. and J. Sprague (1999), Crisis prevention and response: Is your school prepared?, Oregon school study council 43(2): 1-25.

27. Peacock, W. G., S. D. Brody, et al. (2005), Hurricane risk perceptions among Florida's single family homeowners, Landscape and Urban Planning 73(2-3): 120-135.

28. Pereznieto, P. and J. H. Harding (2013), Investing in Youth in International Development Policy: Making the case, London, Overseas Development Institute (ODI).

29. Pereznieto, P. and J. H. Harding (2013), Youth and international development policy: the case for investing in young people, London, Overseas Development Institute (ODI).

30. Preacher, K. and R. MacCallum (2002), Exploratory Factor Analysis in Behavior Genetics Research: Factor Recovery with Small Sample Sizes, Behavior Genetics 32(2): 153-161.

31. Reeves, M. A., L. M. Kanan, et al. (2010), Comprehensive planning for safe learning environments: A school professional's guide to integrating physical and psychological safety, prevention through recovery, Routledge.

32. Ryan, M., N. Campbell, et al. (1999), Continuing professional education and interacting variables affecting behavioral change in practice: instrument development and administration, Journal of continuing education in nursing 30(4): 168-175; quiz 190-161.

33. Seyle, D. C., C. S. Widyatmoko, et al. (2013), Coping with natural disasters in Yogyakarta, Indonesia: A study of elementary school teachers, School Psychology International 34(4): 387-404.

34. Terpstra, T. (2011), Emotions, Trust, and Perceived Risk: Affective and Cognitive Routes to Flood Preparedness Behavior, Risk Analysis 31(10): 1658-1675.

35. UNESCO (2003), Education in situations of emergency, crisis, and reconstruction, UNESCO Strategy, Paris, Division of Policies and Strategies of Education.

36. Velicer, W. F. and J. L. Fava (1998), Effects of variable and subject sampling on factor pattern recovery, Psychological Methods 3(2): 231251.

37. Wang, J. and H. Yuan (2011), Factors affecting contractors' risk attitudes in construction projects: Case study from China, International Journal of Project Management 29(2): 209-219.

38. Yong, A. G. and S. Pearce (2013), A Beginner's Guide to Factor Analysis: Focusing on Exploratory Factor Analysis, Tutorials in Quantitative Methods for Psychology 9(2): 79-94. 
39. Yusuf, A. A. and H. A. Francisco (2009), Climate change vulnerability mapping for Southeast Asia, Singapore, Economy and Environment Program for Southeast Asia (EEPSEA). 